\title{
Tailoring treatment of nonsmall cell lung cancer by tissue type: role of pemetrexed
}

This article was published in the following Dove Press journal:

Pharmacogenomics and Personalized Medicine

19 June 2009

Number of times this article has been viewed

\author{
Steven F Powell' \\ Arkadiusz Z Dudek ${ }^{2}$ \\ 'Department of Medicine, University \\ of Minnesota, Minneapolis, MN, USA; \\ ${ }^{2}$ Division of Hematology, Oncology \\ and Transplantation, University of \\ Minnesota, Minneapolis, MN, USA
}

\begin{abstract}
Pemetrexed (ALIMTA, LY231514, MTA) is a novel multitargeted antifolate that is currently approved for the treatment of metastatic nonsmall cell lung cancer (NSCLC). Recent evidence reveals that the drug's efficacy is limited to nonsquamous lung cancer histology. As we further understand the drug's mechanisms of action, new genomic and proteomic evidence is shedding light on why some patients respond while others do not. The first goal of this review is to briefly review pemetrexed's mechanism of action, resistance patterns, toxicity profile, and pharmacokinetics. We will also review the clinical trials that led to its use in NSCLC, with special attention to data showing that pemetrexed has greater efficacy in nonsquamous histologies of NSCLC. Furthermore, we will discuss the hypotheses for the genomic and proteomic basis for this variation in efficacy. Finally, we will report the future directions for pemetrexed as a personalized agent for nonsquamous NSCLC.
\end{abstract}

Keywords: nonsmall cell lung cancer, pemetrexed, antifoliate

\section{Introduction}

Nonsmall cell lung cancer (NSCLC) is the leading cause of cancer deaths in the United States. The vast majority (approximately 80\%) of patients present with locally advanced disease (Stage III) or metastatic disease (Stage IV). ${ }^{1}$ These patients have a poor overall prognosis, with 5-year survival of less than $15 \%{ }^{2}$ Standard chemotherapy regimens provide only a modest survival benefit. Platinum-based doublet therapies are the mainstay of treatment regimens for NSCLC, with cisplatin and carboplatin being the most frequently utilized. These therapies have been shown to prolong survival, improve quality of life, and provide better symptom control compared to best supportive care (BSC), but their use remains palliative. ${ }^{3}$ In addition to platinum agents, several new agents including vinorelbine, gemcitabine, paclitaxel, and docetaxel have shown utility in treating NSCLC. Despite the array of cytotoxic agents, no specific regimen has shown superiority when looking at overall survival. ${ }^{4}$ The emergence of targeted therapies over the past decade has fueled investigations into their use for NSCLC. Bevacizumab, a recombinant humanized monoclonal antibody, inhibits vascular endothelial growth factor (VEGF), a major regulator of angiogenesis. Its addition to platinum doublets has been shown to add an additional 2 months of survival compared to the standard doublet. 5 Erlotinib, an epithelial growth factor receptor (EGFR) inhibitor, has also shown utility in the treatment of NSCLC. Compared to placebo, it prolonged survival by 2 months in NSCLC patients who had previously been treated with platinum agents. ${ }^{6}$

The advent of targeted therapies raises an interesting question regarding the way we treat NSCLC. Studies of targeted agents have shown that they may have superior use in 
specific populations. For instance, erlotinib has been shown to have superior benefit in patients who were never smokers. A further look into this revealed that non-smokers frequently had sensitizing mutation in EGFR to erlotinib. Conversely, smokers have a higher incidence of $K$-ras mutations. $K$-ras is a downstream effector of the EGFR pathway and when it is mutated, the effect of erlotinib is muted. ${ }^{7}$ Understanding the molecular background of these different groups is paving the way towards tailored therapy for NSCLC. Technological advances in the fields of genomics and proteomics are making this endeavor possible. As new drugs are developed through preclinical and clinical research, researchers are working concurrently to understand the biological basis for responders and non-responders.

Pemetrexed (LY231514, Alimta ${ }^{\circledR}$; Eli Lilly and Company) is a prime example of a new drug under investigation regarding its activity on the molecular level as well as in a clinical setting. The drug is a novel multitargeted antifolate that has shown significant activity in patients with NSCLC as well as a variety of other solid malignancies. A further look into its activity has revealed that its effects seem to be most pronounced in lung adenocarcinomas, with minimal activity in those with squamous cell histologies. ${ }^{8}$ Reviewing how pemetrexed works gives insight into why its activity varies with tissue type.

\section{Pemetrexed - a novel antifolate}

Pemetrexed is a new generation antifolate that inhibits multiple targets involved in folate metabolism. Antifolate drugs in the past have typically targeted and inhibited a single enzyme involved with folate metabolism. All living cells require folic acid and appropriate folate metabolism for cell growth. Specifically, folate metabolism is integral to purine, thymidine, and amino acid biosynthesis. ${ }^{9}$ Perhaps the most widely understood and used antifolate, cancer therapeutic is methotrexate. Methotrexate competitively and reversibly inhibits dihydrofolate reductase (DHFR), an enzyme that participates in the tetrahydrofolate synthesis. ${ }^{10}$ This antimetabolic effect has shown great utility in the treatment in a variety of cancers including leukemias, lymphomas, osteosarcoma, breast cancer, colorectal cancer, urothelial cell cancer, head and neck cancer, and choriocarcinoma. ${ }^{11}$ Because of its impact on cancer therapy, methotrexate has been a model for trying to develop new antifolate drugs. A large number of similar antifolate drugs have been developed, but none to date have matched the clinical efficacy and side effect profile or methotrexate. ${ }^{12}$ This was true until the development of pemetrexed.

\section{Pharmacology/mode of action}

A look into the pharmacology of pemetrexed is enlightening to its potency as an antifolate. The drug enters the cell through the reduced folate carrier at a rapid rate. Also, owing to its high affinity for folate receptors, pemetrexed enters the cell through endocytosis medicated by folate receptor- $\alpha .{ }^{13}$ A low $\mathrm{pH}$ transporter provides a third method for pemetrexed to enter the cell. ${ }^{10}$ After pemetrexed enters the cell, a critical step occurs when it is polyglumated by folylpolyglutamate synthase (FPGS). Methotrexate is polyglutamated in a similar manner, but pemetrexed has a much high affinity for this enzyme. ${ }^{10}$ Pemetrexed's high affinity for FPGS results in significantly more rapid polyglutamation than methotrexate. This is important as the polyglutamated forms of this drug display strong inhibitory effects on a variety of enzymes. These enzymes and their place in folate metabolism are outlined in Figure 1. The polyglutamated derivatives of pemetrexed are strong inhibitors of thymidylate synthase (TS). This is the primary mechanism of action of the drug. 5-flurouracil (5-FU) works in the same manner. Inhibition of TS disrupts the transformation of deoxyuridine monophosphate (dUMP) to deoxythymidine monophosphate (dTMP). ${ }^{14}$ This ultimately decreases the amount of thymidine made for DNA synthesis and therefore inhibits cell growth. The higher the degree of polyglutamation, the more TS is inhibited by pemetrexed. This effect of polyglutamation holds true for many of the other enzymes pemetrexed inhibits. ${ }^{15}$

In addition to TS inhibition, pemetrexed has secondary inhibition of glycinamide ribonucleotide formyltransferase (GARFT), aminoimidazole caroxamide ribonucleotide formyltransferase (AICARFT), and DHFR. Inhibition of GARFT and AICARFT, causes a decrease in de novo purine biosynthesis. ${ }^{16}$ The degree of polyglutamation plays an important role in the inhibition of these enzymes. Polyglutamation has a smaller effect on pemetrexed's inhibition of DHFR. Similar to methotrexate, pemetrexed inhibits DHFR and thus decreases tetrahydrofolate synthesis. It does this to a much lesser degree than methotrexate. ${ }^{17}$ The drug's ability to inhibit multiple enzymes involved in folate metabolism allows it multiple mechanisms in which to inhibit cell growth and proliferation. This is important for the drug's antitumor activity. For example, the drug is active against H630 colon cancer cells in vivo, which are resistant to 5-FU owing to increased TS levels. ${ }^{18}$ This suggests that the other inhibitory pathways play an important role in the drug's activity.

\section{Pharmacokinetics}

Pemetrexed has a terminal half-life is 3.5 hours. Because it is excreted by kidneys, an alteration in renal function can 


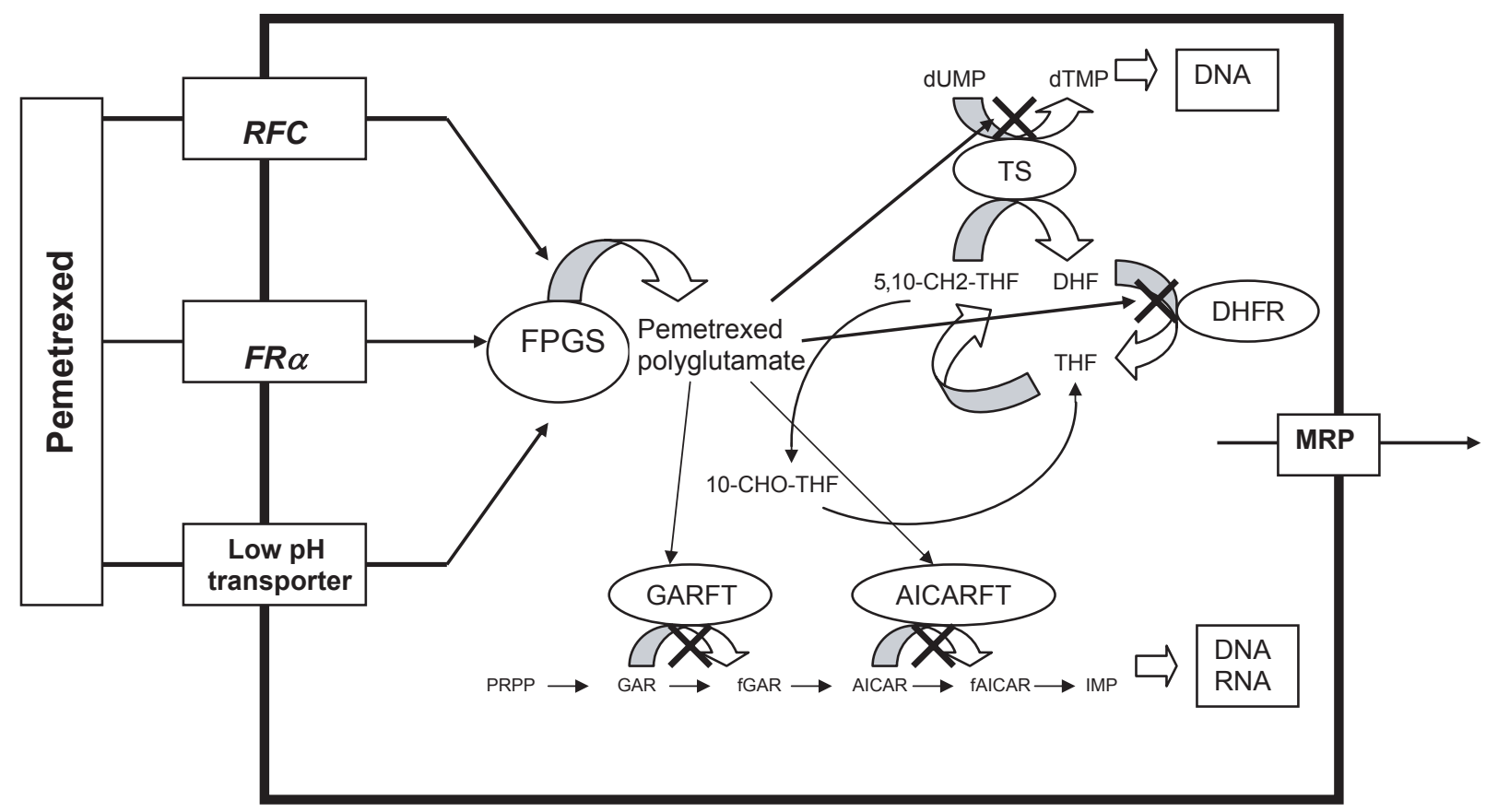

Figure I Targets for pemetrexed in folate metabolism. Pemetrexed is transported into the cell via the reduced folate carrier (RFC), folate receptor- $\alpha$ (FR $\alpha$ ), and the low pH transporter. The drug is transferred out of the cell by the multidrug resistance protein (MRP) through an efflux mechanism. Once inside the cell, the drug is polyglutamated into its more active form by folylpolyglutamate synthase (FPGS). The polyglutamated derivatives of pemetrexed strongly inhibit thymidylate synthase (TS), thus disrupting the transformation of deoxyuridine monophosphate (dUMP) to deoxythymidine monophosphate (dTMP). The drug also causes secondary inhibition of glycinamide ribonucleotide formyltransferase (GARFT), aminoimidazole caroxamide ribonucleotide formyltransferase (AICARFT), and DHFR. Inhibition of GARFT and AICARFT decreases de novo purine biosynthesis, while inhibition of DHFR inhibits tetrahydrafolate (THF) synthesis.

Abbreviations: PRPP, phosphoribosyl pyrophosphate; GAR, glycinamide ribonucleotide; fGAR, N-formylglycinamide ribonucleotide; AICAR, 5-aminoimidazole-4-caroxamide ribonucleotide; fAICAR, 5-formylaminoimidazole-4-caroxamide ribonucleotide; IMP, inosine monophosphate.

change the drug's half-life. The drug is approximately $81 \%$ bound to plasma proteins. The drug is excreted in the urine with $70 \%$ to $90 \%$ of the dose recovered as unchanged parent drug after 24 hours. ${ }^{19}$ Pemetrexed has limited metabolism in the liver; however no relationship between transaminases or bilirubin conjugation correlate with the degree of metabolism of the drug. ${ }^{20}$ To date there have been no reported alterations in the pharmacokinetics of pemetrexed in adult patients with varying age, ethnicity (black or white), or sex. ${ }^{21}$

\section{Mechanisms of resistance}

Pemetrexed's mutitargeted mechanism of action affords the drug the ability to be active in a variety of cell lines that are typically resistant to antimetabolites. Despite this benefit, drug resistance mechanisms to pemetrexed have been noted. Multidrug resistance proteins (MRP) 2 and 5 have been noted to act on pemetrexed. ${ }^{22}$ These are known drug resistance proteins that decrease the intracellular levels of drugs through and efflux pump mechanism. Additionally, any inhibition of polyglutamation or alteration of the polyglutamated forms of pemetrexed will diminish its activity by decreasing its affinity for target enzymes. In L1210 leukemia cells, it was noted that either decreased levels or efficiency of FPGS resulted in less polyglutamated pemetrexed. ${ }^{23}$ Additionally, the enzyme folypolyglutamate hydrolase has been shown to hydroxylate pemetrexed polyglutamates. ${ }^{24}$ Both of these mechanisms decrease levels of polyglutamated pemetrexed, which in essence will limit its activity.

Competitive inhibition of the target enzymes of pemetrexed can also cause decreased activity of the drug. Folic acid levels can have a direct effect on the efficacy of pemetrexed. High levels of intracellular folic acid derivatives can cause competitive inhibition of FPGS and thus inhibit polyglutamation of pemetrexed. ${ }^{25}$ On the other hand, low levels of folic acid derivatives may enhance the effect of the drug. This poses an interesting question regarding what the folate status should be for patients receiving the drug. Several studies have evaluated this question and will be discussed later on.

\section{Safety and tolerability Toxicity/adverse reactions}

Myelosuppression, rash, fatigue, and gastrointestinal toxicity are the most common toxicities with pemetrexed. 
Neutropenia/granulocytopenia is the most common and severe myelosuppressive event when pemetrexed is used alone or in combination with other drugs. ${ }^{21}$ Thrombocytopenia and anemia occur to a lesser degree, but are still fairly common. The rash seen with pemetrexed is typically mild (grade 1-2) and responds well to pretreatment with dexamethasone. Gastrointestinal toxicities are prevalent and include from most common to least common: nausea, anorexia, vomiting, stomatitis, and diarrhea (grade 1-2). Renal toxicities are minimal, occurring in $1 \%$ to $5 \%$ of patients, and are manifested as elevation of the serum creatinine. ${ }^{21}$ Other uncommon adverse effects include transaminitis, fever, and alopecia. ${ }^{21}$ Most of these toxicities are similar to other chemotherapeutic agents for NSCLC. Overall, it has been shown that pemetrexed's side effects seem to be less severe and the drug is well tolerated when compared to other agents for NSCLC. An example of this can be noted in Table 1 where grade 3-4 toxicities are compared in pemetrexed and docetaxel. Ultimately, myelosuppression remains the major dose-limiting factor of the drug.

\section{Vitamin BI2 and folic acid supplementation}

Because of pemetrexed's role in the folate pathway, the addition of vitamin B12 and folate to supplement treatment

Table I Grade 3 and 4 adverse reactions in patients receiving pemetrexed versus docetaxe ${ }^{21}$

\begin{tabular}{lll}
\hline Reaction & $\begin{array}{l}\text { Pemetrexed } \\
(\mathbf{N}=\mathbf{2 6 5})\end{array}$ & $\begin{array}{l}\text { Docetaxel } \\
(\mathbf{N}=\mathbf{2 7 6})\end{array}$ \\
\hline Hematologic & 4 & 4 \\
Anemia & 4 & 27 \\
Leukopenia & 5 & 40 \\
Neutropenia & 2 & 0 \\
Thrombocytopenia & & \\
Hepatic & 2 & 0 \\
Increased ALT & 1 & 0 \\
Increased AST & & 2 \\
Gastrointestinal & 3 & 3 \\
Nausea & 2 & 1 \\
Anorexia & 2 & 1 \\
Vomiting & 1 & 3 \\
Stomatitis/pharyngitis & 0 & 2 \\
Diarrhea & & \\
Constitutional symptoms & 5 & \\
Fatigue & & \\
Dermatology/skin & & \\
Alopecia & &
\end{tabular}

regimens has been investigated as a means of decreasing toxicity. An analysis was performed early on in pemetrexed's development that assessed relationships between vitamin metabolites, drug exposure, patient characteristics, and toxicity after therapy with pemetrexed. ${ }^{19}$ Data from this study suggested that toxicity with pemetrexed was higher in patients with elevated pre-therapy homocysteine levels. Based on this information, it was recommended that patients receive vitamin supplementation prior to and during therapy. The current recommended dose is folic acid, 350 to $1000 \mu \mathrm{g}$ daily, starting 7 days prior to initiation of chemotherapy and continued through treatment until at least 21 days after the end of therapy. Vitamin B12 supplementation is recommended to be given intramuscularly at a dose of $1000 \mu \mathrm{g}$ with the first dose 1 week prior to chemotherapy and then subsequent doses every 3 cycles during therapy. Studies incorporating supplementation of vitamin B12 and folate have shown improved side effect profiles in both combination and monotherapies utilizing pemetrexed. ${ }^{21}$ Table 2 shows an example of this difference.

Additional work has been done regarding vitamin supplementation in patients receiving pemetrexed. One pre-clinical study evaluated the hypothesis that elevated serum folate levels may limit the efficacy of pemetrexed. ${ }^{27}$ This study found that tumor cell growth inhibition decreased as the extracellular folate level increased over the physiologic range of folate blood levels. Additionally, the study pointed out that many foods in the US are supplemented with folic acid and this may in turn elevate serum folate levels without additional supplementation, and made the recommendation that folic acid supplementation in patients being treated with pemetrexed should be dosed at the lowest level needed to provide protection from pemetrexed toxicity. For vitamin B12 supplementation, a phase II clinical study recently looked at the time of initiation of vitamin B12 and the difference in toxicity as a secondary endpoint. ${ }^{28}$ The study ultimately found that there was no significant difference in toxicities when vitamin B12 was given at less than the recommended 7 days prior to initiation of treatment. The results of these studies have led to the development of an ongoing study (Eli Lilly S-111) that is looking at the effects of reducing and simplifying vitamin supplementation in patients treated with pemetrexed.

\section{Pemetrexed as therapy for NSCLC}

Pemetrexed has been evaluated for its use in a variety of tumor types. It is currently approved for use in patients with malignant pleural mesothelioma and NSCLC. The focus of 
Table 2 Effects of vitamin BI2 and folic acid supplementation on reducing grade 3-4 adverse events in patients receiving pemetrexed plus cisplatin ${ }^{21}$

\begin{tabular}{lll}
\hline Adverse event (\%) & Fully supplemented & $\begin{array}{l}\text { Never supplemented } \\
\text { patients }(\mathbf{N}=\mathbf{3 2})\end{array}$ \\
\hline Neutropenia/granulocytopenia & patients $(\mathbf{N}=168)$ & 38 \\
Thrombocytopenia & 23 & 9 \\
Vomiting & 5 & 31 \\
Febrile neutropenia & 11 & 9 \\
Infection with grade 3-4 neutropenia & 1 & 6 \\
Diarrhea & 0 & 9 \\
\hline
\end{tabular}

this review is on NSCLC. The drug has also been studied in patients with pancreatic, colorectal, breast, gastric, genitourinary, and head and neck cancers. ${ }^{21}$ A number of clinical trials have been done looking at single-agent pemetrexed used as first-line and second-line therapy for NSCLC. Additional studies have evaluated the drug as part of several combination chemotherapy regimens. Several of these studies have analyzed the responses in various histologic subtypes of NSCLC. This review will outline the clinical studies that evaluated pemetrexed. When possible, it will highlight the difference in response in the various histologic subtypes of NSCLC.

\section{First-line therapy}

\section{Single-agent pemetrexed}

There have been a number of trials evaluating pemetrexed as a single-agent. Several of these studies are listed in Table 3. The first single-agent pemetrexed study was a phase II clinical trial done in $1999 .{ }^{26}$ This study involved treating previously untreated patients with advanced NSCLC with pemetrexed at a dose of $600 \mathrm{mg} / \mathrm{m}^{2} \mathrm{IV}$ over 10 minutes for every 3 weeks. Early on in the study, the dose had to be reduced to $500 \mathrm{mg} / \mathrm{m}^{2}$ due to toxicity. A total of 33 patients were enrolled in the trial and 30 were assessable for response. Seven patients had a partial response; however no patients had a complete response. The overall response rate of this study was $23.3 \%$. The median survival was 9.2 months with a median time to disease progression of 3.8 months. Overall 1 -year survival for the study was $25 \%$.

A second phase II clinical trial looking at pemetrexed as a single-agent in chemotherapy-naïve patients with advanced NSCLC was reported in 2002. ${ }^{29}$ In this study, a total of 59 patients received pemetrexed at a dose of $600 \mathrm{mg} / \mathrm{m}^{2} \mathrm{IV}$ every 3 weeks. Nine patients out of 57 who were assessable for response had partial responses for an overall response rate of $15.8 \%$. Median time to disease progression was 4.4 months, while the median survival 7.2 months. The overall 1 -year survival was $32 \%$. There was no vitamin B12 or folic acid supplementation provided in either of these studies.

A recent randomized phase II study evaluated the use of pemetrexed vs pemetrexed with gemcitabine in chemotherapy naive NSCLC patients who were elderly ( $>70$ years old) or who were younger than 70 and not

Table 3 Clinical trials evaluating pemetrexed as a single-agent in advanced NSCLC

\begin{tabular}{|c|c|c|c|c|c|c|c|}
\hline Trial & Phase & $\begin{array}{l}\text { Pemetrexed dose } \\
\text { (based on a } 2 \text { I-day cycle) }\end{array}$ & $\begin{array}{l}\text { Number } \\
\text { of patients }\end{array}$ & $\begin{array}{l}\text { ORR } \\
(C R+P R)\end{array}$ & $\begin{array}{l}\text { Median survival } \\
\text { (months) }\end{array}$ & $\begin{array}{l}\text { TTDP } \\
\text { (months) }\end{array}$ & $\begin{array}{l}\text { I-year } \\
\text { survival }\end{array}$ \\
\hline Rusthoven ${ }^{26}$ & II & $\begin{array}{l}600 \mathrm{mg} / \mathrm{m}^{2} \text { (changed to } \\
500 \mathrm{mg} / \mathrm{m}^{2} \text { ) }\end{array}$ & 30 & $23.3 \%$ & 9.2 & 3.8 & $25 \%$ \\
\hline Clarke $^{29}$ & II & $600 \mathrm{mg} / \mathrm{m}^{2}$ & 57 & $15.8 \%$ & 7.2 & 4.4 & $32 \%$ \\
\hline Gridelli $i^{30}$ & II & $500 \mathrm{mg} / \mathrm{m}^{2}$ & 44 & $4.5 \%$ & 4.7 & NR & $28.5 \%$ \\
\hline Smit ${ }^{43}$ & II & $500 \mathrm{mg} / \mathrm{m}^{2}$ & 79 & $8.9 \%$ & 5.7 & 2.0 & $23 \%$ \\
\hline Hanna $^{45}$ & III & $500 \mathrm{mg} / \mathrm{m}^{2}$ & $\begin{array}{l}571 \\
(283 \text { pemetrexed) }\end{array}$ & $9.1 \%$ & 8.3 & 3.4 & $29.7 \%$ \\
\hline Cullen ${ }^{49}$ & III & $\begin{array}{l}500 \mathrm{mg} / \mathrm{m}^{2} \text { (P500) vs } \\
900 \mathrm{mg} / \mathrm{m}^{2} \text { (P900) }\end{array}$ & $\begin{array}{l}588 \text { total, (295 P500 } \\
\text { and } 293 \text { P900) }\end{array}$ & $\begin{array}{l}7.1 \%(P 500) \\
4.3 \%(P 900)\end{array}$ & $\begin{array}{l}6.7 \text { (P500), } 6.9 \\
(P 900)\end{array}$ & NR & $\begin{array}{l}26.0 \% \text { (P500), } \\
25.1 \%(P 900)\end{array}$ \\
\hline
\end{tabular}

Abbreviations: NR, not reported; ORR, overall response rate; CR, complete response; PR, partial response; TTDP, time to disease progression. 
eligible for platinum therapy. ${ }^{30}$ The patients treated with pemetrexed alone were treated with the $500 \mathrm{mg} / \mathrm{m}^{2}$ dose on a 3-week cycle. All patients were given vitamin B12 and folate supplementation in this study. A total of 87 patients received therapy with 44 receiving pemetrexed alone and 43 receiving pemetrexed/gemcitabine. Of the 44 patients receiving pemetrexed alone, the tumor response rate was $4.5 \%$. The median time to disease progression was $4.5 \%$ in the pemetrexed alone group, while the median survival was 4.7 months. The 1-year survival rate in this study for the pemetrexed alone arm was $28.5 \%$.

In these studies, grade 3-4 hematologic toxicities were the most common findings. After looking at each study, neutropenia was the most common finding, 39\%-42\% of patients experiencing grade 3-4 toxicity. Febrile neutropenia varied from $3 \%$ to $13.3 \%$ of patients. Thrombocytopenia was much less common, at $3 \%$ to $5 \%$. The most common grade 3-4 nonhematologic toxicity was a cutaneous rash seen in approximately $31 \%$ to $39 \%$ of patients. Grade $1-2$ toxicities that were commonly found in patients included stomatitis, diarrhea, lethargy, anorexia, transaminitis, and fevers.

\section{Platinum-based therapies}

Platinum-based combination therapies are the current standard for the treatment of advanced NSCLC. ${ }^{3}$ This principle has led to the development of studies of several platinum-based combination therapies utilizing pemetrexed. The first phase II study of a platinum-based combination was reported in $2000 .{ }^{31}$ In this study, 36 therapy naive patients with advanced NSCLC (stage IIIB and Stage IV) were treated with pemetrexed at a dose of $500 \mathrm{mg} / \mathrm{m}^{2}$ and cisplatin at a dose of $75 \mathrm{mg} / \mathrm{m}^{2}$ on a 21-day cycle. The overall response rate was $39 \%$. The median time to disease progression was 6.3 months. Median overall survival was 10.9 months and overall 1-year survival was $50 \%$. A second similar study was done in Canada and reported in 2001. ${ }^{32}$ This study involved a similar patient population who were therapy naïve with advanced NSCLC. The dosing was the same as the prior study with pemetrexed at a dose of $500 \mathrm{mg} / \mathrm{m}^{2}$ and cisplatin at a dose of $75 \mathrm{mg} / \mathrm{m}^{2}$ delivered on a 21-day cycle. A total of 31 patients were evaluated for response. The overall response rate was $45 \%$ and median overall survival was 8.9 months. Median duration of response was 6.1 months. The overall 1-year survival was $49 \%$.

The important aspect of these studies was that the toxicity of the combination regimens was not significantly higher than of other regimens. Cytopenias were the most common adverse event. In the first study, 59\% of patients had grade 3-4 granulocytopenia and $17 \%$ had grade $3-4$ thrombocytopenia. ${ }^{31}$ In the second study, grade 3-4 granulocytopenia was seen in $33 \%$ of patients, while grade 3-4 thrombocytopenia was seen in only 1 patient ( $3 \%){ }^{32}$ These findings are similar to those seen in pemetrexed as a single agent, but more prevalent.

\section{Gemcitabine}

Gemcitabine is another active agent in NSCLC. In 2004, the first phase II study evaluating pemetrexed and gemcitabine was reported. ${ }^{33}$ This study included chemotherapy naïve patients with stage IIIB or IV NSCLC. The patients received gemcitabine $1250 \mathrm{mg} / \mathrm{m}^{2}$ on days 1 and 8 , and pemetrexed $500 \mathrm{mg} / \mathrm{m}^{2}$ on day 8 for a cycle of 21 days. The patients in this study received vitamin B12 and folic acid supplementation. A total of 58 patients were evaluated for response. The reported overall response rate for evaluated patients was $15.5 \%$. Median overall survival was 10.1 months and 1 -year survival was $42.6 \%$. The median duration of response in responding patients was 3.3 months. Common grade 3-4 toxicities were noted to be neutropenia (61.7\%), febrile neutropenia (16.7\%), fatigue (23.3\%), and elevations of aspartate aminotransferase (15.0\%) and alanine aminotransferase (20.0\%). Based on these data the elevation in transaminases appears to be more severe when gemcitabine is added to pemetrexed. Additionally, grade 3-4 neutropenia occurred more often when adding gemcitabine.

The dosing regimen was challenged in a phase II study reported in 2005. ${ }^{34}$ This study looked at three different schedules for administering the pemetrexed and gemcitabine combination in chemotherapy-naïve patients. Doses were pemetrexed $500 \mathrm{mg} / \mathrm{m}^{2}$ and gemcitabine $1250 \mathrm{mg} / \mathrm{m}^{2}$ for all groups. Schedule A received pemetrexed followed 90 minutes later by gemcitabine on day 1 plus gemcitabine on day 8 . Schedule B received gemcitabine followed 90 minutes later by pemetrexed on day 1 plus gemcitabine on day 8 . Schedule $\mathrm{C}$ received gemcitabine on day 1 plus pemetrexed followed 90 minutes later by gemcitabine on day 8 . The results of this study suggested that schedule A was preferred over the other schedules based on the toxicity. Each group had a variety of responses, which are noted in Table 4. Further phase II and III clinical studies looking at gemcitabine and pemetrexed in combination for NSCLC have been done using similar schedules as the previously motioned phase II clinical trials. The results of several of these studies can be found in Table $4 .{ }^{35-40}$

\section{Vinorelbine}

Vinorelbine is a semi-synthetic vinca alkaloid that has shown activity in NSCLC as part of a platinum-based 


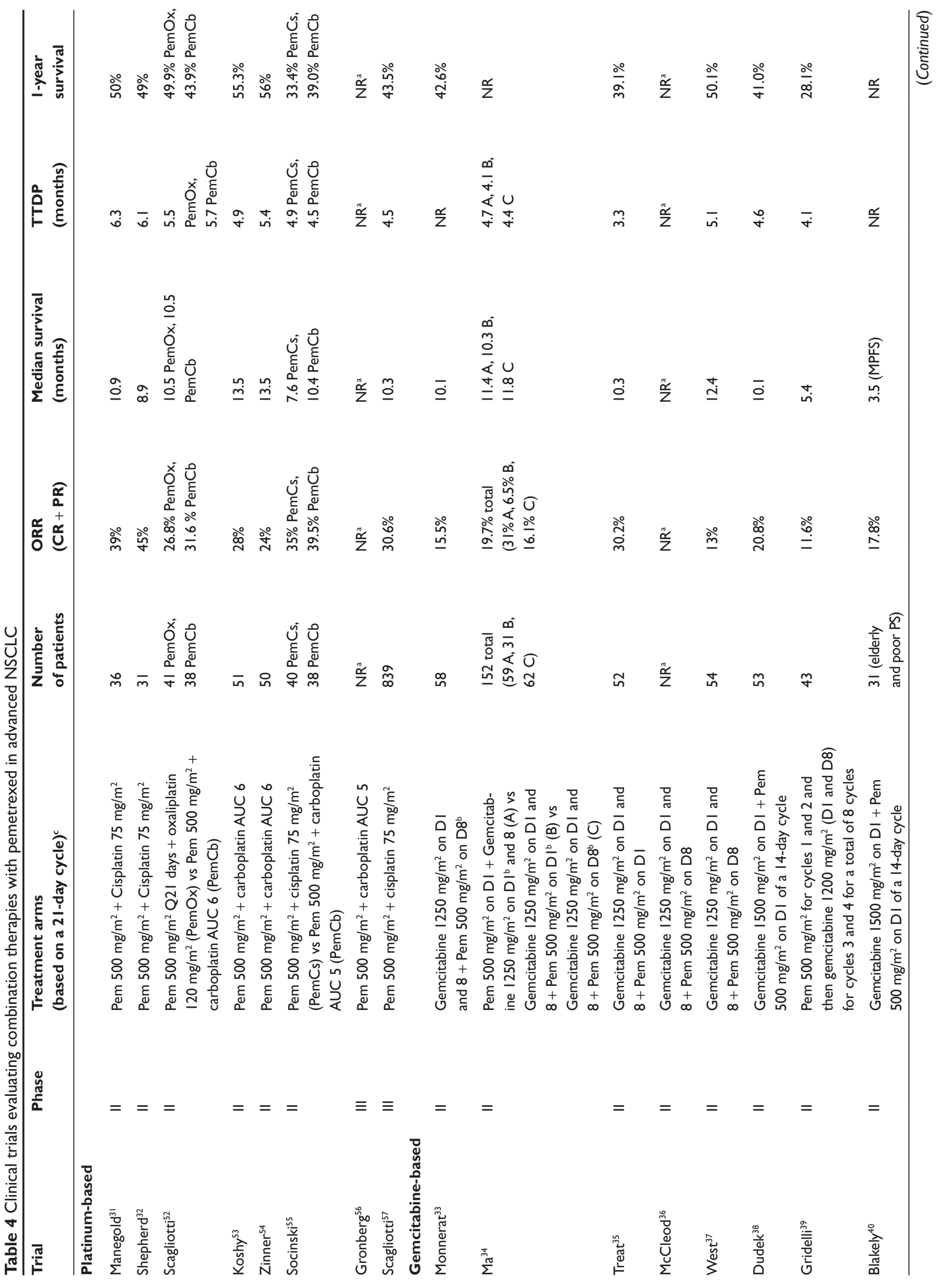




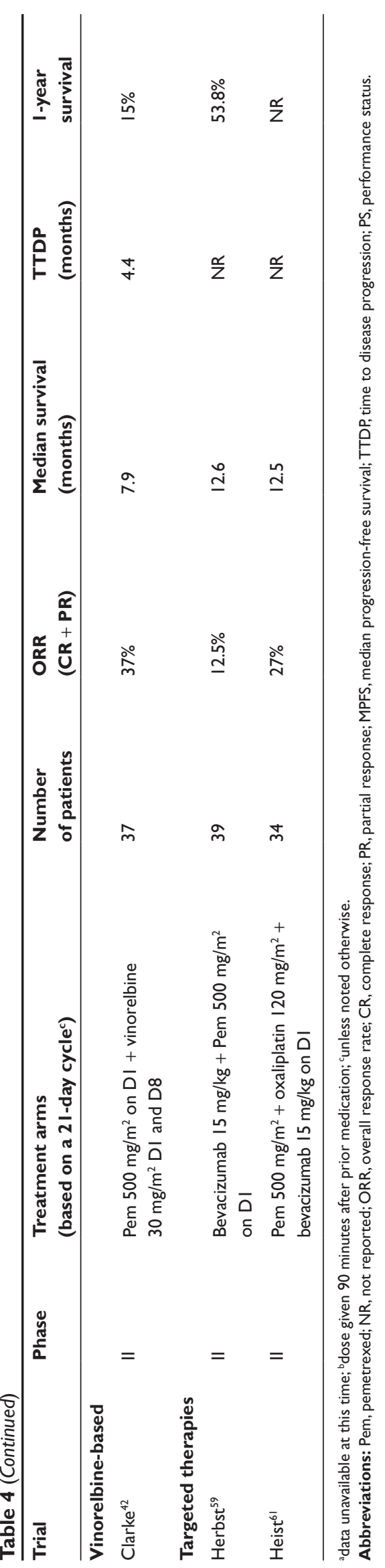

combination regimen. ${ }^{41}$ A combination regimen of vinorelbine and pemetrexed was evaluated in a phase I/II clinical trial reported in $2005 .{ }^{42}$ The study looked at the combination as both first- and second-line therapy, however in the phase II portion; the majority of patients (97\%) received the combination as first-line chemotherapy. In the phase II portion of the study, a total of 37 patients received pemetrexed at a dose of $500 \mathrm{mg} / \mathrm{m}^{2}$ on day 1 and vinorelbine at a dose of $30 \mathrm{mg} / \mathrm{m}^{2}$ on days 1 and 8 for a 21 -day cycle. The overall response rate was $37 \%$ and the median survival time was 7.9 months. The median time to disease progression was 4.4 months. Estimated 1-year survival was $15 \%$. Common grade 3-4 toxicities included neutropenia (65\%), febrile neutropenia (11\%), and fatigue (21\%). The results of this study are outlined in Table 4.

\section{Second-line therapy} Single-agent pemetrexed

Several studies have been performed to evaluated single-agent pemetrexed as second-line therapy for NSCLC. The first such study was a phase II clinical trial that evaluated pemetrexed at a dose of $500 \mathrm{mg} / \mathrm{m}^{2}$ on a 3 week cycle. ${ }^{43}$ The patients were grouped based on whether or not their previous treatment regimen had included a platinum agent. A total of 79 patients were able to be assessed. The response rate for all patients was $8.9 \%$, with the response rate being $4.5 \%$ in the platinum-pretreated group and $14.1 \%$ in the nonplatinumpretreated group. Medial survival was 5.7 months overall, with 6.4 months for the platinum-pretreated group and 4 months for the nonplatinum-pretreated group. Median time to disease progression was 2.0 months overall, 2.3 months in the platinum-pretreated group, and 1.6 months in the nonplatinum-pretreated group. One-year survival was $23 \%$ overall, $25 \%$ for the platinum-pretreated group, and $20 \%$ for nonplatinum-pretreated group. The overall response rate of $9 \%$ was seen to be favorable when compared to docetaxel, the standard second-line therapy at that time, with an overall response rate of $7 \%{ }^{44}$

The findings from these studies led to a randomized phase III clinical trial that comparing pemetrexed and docetaxel used as a single-agent as second line therapy for NSCLC. This study included 571 randomly assigned patients with previously treated NSCLC. ${ }^{45}$ The two groups received pemetrexed $500 \mathrm{mg} / \mathrm{m}^{2}$ on a 3-week cycle or docetaxel $75 \mathrm{mg} / \mathrm{m}^{2}$ on a 3 -week cycle. The pemetrexed group was supplemented with vitamin B12 and folic acid. The overall response rates were essentially identical in both groups at $9.1 \%$ for the pemetrexed arm and $8.8 \%$ for the docetaxel 
arm. Median time to disease progression was also the same at 3.4 months for pemetrexed and 3.5 months for docetaxel. Median overall survival was slightly higher in the pemetrexed group at 8.3 months vs 7.9 months; however the results were not statistically significant. The 1 -year survival rate was identical in both groups at $29.7 \%$. Pemetrexed was found to be better tolerated in this study than docetaxel, especifically for a lower incidence of grade 3 or 4 neutropenia and neutropenic fevers. This information eventually led to pemetrexed being approved as monotherapy as second-line treatment for patients with locally advanced or metastatic NSCLC. ${ }^{46}$

Two retrospective analyses have looked at this important study further to look at quality of life outcomes. One analysis looked at lung cancer symptom scale outcomes in these patients. ${ }^{47}$ The analysis found that in patients who responded or who had stable disease, ultimately had improvement of their lung cancer symptoms, with exception to hemoptysis. The return of symptoms correlated with disease progression findings as well. Another retrospective analysis of this study looked at differences in survival time without grade 3-4 toxicities. ${ }^{48}$ This analysis revealed that there was a statistically significantly longer survival without grade 3-4 toxicity in patients treated with pemetrexed vs those treated with docetaxel (hazard ratio $=0.60$, [95\% CI: 0.50 to 0.72$]$ $P=0.0001)$. Specifically patients treated with pemetrexed had less incidents of neutropenia lasting 5 days, febrile neutropenia, infection with neutropenia, cytopenias, fatigue, nausea, vomiting, diarrhea, stomatitis, and neurosensory effects. These two retrospective analysis added support to already reported findings that pemetrexed may be better tolerated than docetaxel.

Further work has been done since this study regarding single-agent pemetrexed. Perhaps the most interesting was a recent randomized phase III study evaluating the effect of escalating the dose of pemetrexed. ${ }^{49}$ The study randomized patients to receive the standard dose of pemetrexed of $500 \mathrm{mg} / \mathrm{m}^{2}$ on a 3-week cycle vs a dose of $900 \mathrm{mg} / \mathrm{m}^{2}$ on a 3-week cycle. Patients in the study had advanced NSCLC that progressed on a platinum-containing regimen. A total of 588 patients were eligible to enter the study. Of these patients 295 received the standard pemetrexed dose and 293 received the escalated dose. The results of the study found that there was no difference between the two groups for overall survival or progressionfree survival. The overall response rate was higher in the standard dose group at $7.1 \%$ than in the higher dose group at $4.3 \%$; however these results were not found to be statistically significant. These data suggest that the standard dose of $500 \mathrm{mg} / \mathrm{m}^{2}$ every 3 weeks should not be changed.

\section{Platinum-based therapies}

Data from the previously mentioned studies looking at platinum-containing regimens in combination with pemetrexed $^{50,51}$ as first-line therapy led to further phase II and phase III studies of combinations of pemetrexed with cisplatin, oxaliplatin, and carboplatin. ${ }^{52-57}$ The results of these studies are outlined in Table 4. The studies also stimulated thought into whether the addition of pemetrexed to a platinum agent may be beneficial as second-line therapy.

An important study comparing second-line pemetrexed with pemetrexed/carboplatin (PC) was recently reported..$^{58}$ This was a phase II study looking at the difference in response, time to progression, and toxicity in previously platinum-treated patients. Patients were randomized to pemetrexed $500 \mathrm{mg} / \mathrm{m}^{2}$ every 3 wks or PC (C AUC 5 and pemetrexed $500 \mathrm{mg} / \mathrm{m}^{2}$ ) given every 3 weeks. The primary outcome was median time to progression, which was noted to be 5.7 months for the pemetrexed only group vs 6.9 months for the pemetrexed plus carboplatin group. The overall response rate was higher in the PC group at 9\% vs $4 \%$ in the pemetrexed only group. Median overall survival was also slightly better in the PC group at 8.1 months vs 7.3 months in the pemetrexed monotherapy group (hazard ratio $=0.8[0.60,1.07], P=0.12)$. Notably, toxicities were higher in the PC group with $44 \%$ of patients experiencing grade 3-4 toxicities vs 29\% in the pemetrexed monotherapy group. The main toxicities experienced were hematologic. Based on these data, it was determined that the combination of pemetrexed and carboplatin did not provide significant reduction in hazard of progression over pemetrexed alone. Additionally, the adverse events were noted to be higher in the combination group. The study suggested that further testing of carboplatin with pemetrexed is not warranted based on their findings.

\section{Targeted therapies}

The recent emergence of targeted therapies has opened an entirely new arena for pemetrexed-based combination therapies. Bevacizumab is a VEGF inhibitor that is approved for use as a second-line therapy for NSCLC. Several studies have been done evaluating this drug used in combination with pemetrexed. The first such study was done in $2007 .{ }^{59}$ In this phase II, randomized, multicentered study, 120 patients were randomly assigned to receive chemotherapy (docetaxel or pemetrexed) alone, bevacizumab with chemotherapy, or bevacizumab plus erlotinib. The drugs were given at their standard dosages. The major finding in this study was that fewer patients discontinued treatment due to toxicity in the 
bevacizumab/erlotinib (13\%) group than the chemotherapy alone group (24\%), or the chemotherapy plus bevacizumab group (28\%). The overall response was $12.2 \%$ in the chemotherapy alone group, $12.5 \%$ in the bevacizumab plus chemotherapy group, and $17.9 \%$ in the bevacizumab plus erlotinib group. Overall survival was 8.6 months for the chemotherapy alone group, 12.6 months for the bevacizumab plus chemotherapy group, and 13.7 months for the bevacizumab plus erlotinib group. One-year survival was $33.1 \%$ for chemotherapy alone, $53.8 \%$ for bevacizumab plus chemotherapy, and $57.4 \%$ for bevacizumab plus erlotinib. Administration of docetaxel over pemetrexed in the chemotherapy arms was up to each institution and response differences for each separate drug were not reported. For toxicity, the most notable finding was that neutropenia occurred in $24.3 \%$ of those in the chemotherapy alone group vs $30.8 \%$ in the chemotherapy/bevacizumab group. Ultimately these findings were noted to be similar to prior toxicity data for each drug when used as a monotherapy.

Another study evaluating bevacizumab with was performed in $2007 .{ }^{60}$ In this study, 25 patients at a single institution were treated with either pemetrexed or pemetrexed/bevacizumab as salvage therapy. Patients were followed for a median follow-up of 9.3 months. There was no statistical difference between the two groups regarding median overall survival, time to disease progression, or objective disease control rate. The 6-month survival was $56.3 \%$ for the pemetrexed group and $66.7 \%$ for the pemetrexed/bevacizumab group. This study suggested that the addition of bevacizumab to pemetrexed was safe, however improvements in efficacy have yet to be determined.

Based on the tolerability of bevacizumab in combination with pemetrexed, a third combination study was recently done. ${ }^{61}$ This multicenter phase II trial evaluated the triple combination of pemetrexed $\left(500 \mathrm{mg} / \mathrm{m}^{2}\right)$, oxaliplatin $\left(120 \mathrm{mg} / \mathrm{m}^{2}\right)$, and bevacizumab $(15 \mathrm{mg} / \mathrm{kg})$ given every 21 days in previously treated advanced NSCLC patients. A total of 34 out of 36 patients were evaluated for response. Of those patients the overall response rate was noted to be $27 \%$. Median overall survival was 12.5 months and median progression-free survival was 5.8 months. The treatment was well tolerated with the most common toxicity being hypertension. These data suggested that the use of pemetrexed in a three-drug regimen has tolerable toxicity profiles.

In addition to bevacizumab, a number of other targeted agents are being evaluated for use in combination with pemetrexed. A recent phase I study of vandetanib, a VEGF inhibitor, used in combination with pemetrexed had a favorable response rate with a relatively low side effect profile. ${ }^{62}$ Also, recent data from a phase I/II study looked at cetuximab, an EGFR inhibitor, in combination with pemetrexed. ${ }^{63}$ This study used alternative dosing of pemetrexed at $750 \mathrm{mg} / \mathrm{m}^{2}$ every 21 days in combination with cetuximab $400 \mathrm{mg} / \mathrm{m}^{2}$ on week 1 and $200 \mathrm{mg} / \mathrm{m}^{2}$ each week thereafter. At the time of the abstract's publication, response data were available for 18 patients. There were partial responses in $8.7 \%$ and stable disease in $34.8 \%$. Median time to disease progression was 25 weeks.

\section{Differences in efficacy based on histologic subtype of NSCLC}

Among the multitude of trials evaluating pemetrexed in NSCLC, patients with all histologic subtypes have been included. It is common for all histologic subtypes to be included in clinical trials for NSCLC. Until recently, subset analysis of response for each histologic subtype was not usually performed.$^{64}$ This is partially due to interesting data presented from two clinical trials utilizing pemetrexed. One of these was a retrospective analysis ${ }^{65}$ of the phase III trial evaluating second-line pemetrexed vs docetaxel..$^{45}$ In this analysis, it was noted that overall survival in patients with squamous cell histology was significantly higher in the docetaxel group at 7.4 months vs 6.2 months in the pemetrexed group. On the other hand, the overall survival remained essentially the same at 9.0 months and 9.2 months for the pemetrexed and docetaxel groups with adenocarcinoma. More interestingly, there was a large difference in overall survival in the large-cell histology group. The pemetrexed-treated group had a median overall survival of 12.8 months, while the docetaxel group only had 4.5 months. Histologies other than these showed median overall survival of 9.4 months in the pemetrexed group and 7.9 months in the docetaxel group. Compilation of the nonsquamous cell types showed favorability for pemetrexed with median overall survival at 9.3 months vs 8.0 months for docetaxel. These data for nonsquamous subtypes were found to favor pemetrexed with statistical significance $(P=0.048)$. The results of this study are noted in Table 5. At the same time these data were published, another study was presented that showed differences in response to pemetrexed based on NSCLC histology. ${ }^{66,67}$ This study was a phase III clinical trial comparing the combinations of pemetrexed/cisplatin (PC) vs gemcitabine/cisplatin (GC) as first-line therapy in patients with advanced NSCLC. Overall, the study found that PC had similar efficacy to GC in advanced NSCLC (overall survival 10.3 months vs 10.3 months); however PC was better tolerated. Further analysis 
Table 5 Pemetrexed-based therapies impact on survival based on NSCLC histologic subtype

\begin{tabular}{|c|c|c|c|c|c|c|}
\hline Trial & Treatment groups & Histologic subtype & & $\begin{array}{l}\text { Number } \\
\text { of patients }\end{array}$ & $\begin{array}{l}\text { Median survival } \\
\text { (months) }\end{array}$ & $\begin{array}{l}\text { Hazard ratio for A vs B } \\
(95 \% \mathrm{Cl})\end{array}$ \\
\hline \multirow[t]{9}{*}{ Peterson ${ }^{65}$} & Pemetrexed (A) vs & Adenocarcinoma & A & 158 & 9.0 & 0.915 (0.685 to I.224) \\
\hline & docetaxel (B) & & B & 144 & 9.2 & \\
\hline & & Large cell & $A$ & 18 & 12.8 & $0.266(0.112-0.633)$ \\
\hline & & & B & 29 & 4.5 & \\
\hline & & Squamous cell & A & 78 & 6.2 & 1.563 (I.079 to 2.264$)$ \\
\hline & & & B & 94 & 7.4 & \\
\hline & & All nonsquamous & A & 205 & 9.3 & 0.778 (0.607 to 0.997$)$ \\
\hline & & & B & 194 & 8.0 & \\
\hline & & & & & $\begin{array}{l}\text { Median survival } \\
\text { (months) }\end{array}$ & $\begin{array}{l}\text { Hazard ratio for A vs B } \\
(95 \% \mathrm{Cl})\end{array}$ \\
\hline \multirow[t]{9}{*}{ Scagliotti 66,67} & Pemetrexed + & Adenocarcinoma & A & 847 & 12.6 & 0.84 (0.7I to 0.99$)$ \\
\hline & cisplatin (A) vs cisplatin + & & B & & 10.9 & \\
\hline & gemcitabine (B) & Large cell & $A$ & 153 & 10.4 & 0.67 (0.48 to 0.96$)$ \\
\hline & & & B & & 6.7 & \\
\hline & & Squamous cell & $A$ & 473 & 9.4 & $1.23(\mathrm{I} .00$ to $\mathrm{I} .5 \mathrm{I})$ \\
\hline & & & B & & 10.8 & \\
\hline & & All nonsquamous & A & 1000 & 11.8 & $0.8 \mathrm{I}$ (0.70 to 0.94$)$ \\
\hline & & & B & & 10.4 & \\
\hline & & & & & $\begin{array}{l}\text { Median survival } \\
\text { (months) }\end{array}$ & $\begin{array}{l}\text { Hazard ratio for A vs B } \\
(95 \% \mathrm{Cl})\end{array}$ \\
\hline \multirow[t]{3}{*}{ Peng $^{68}$} & Pemetrexed + carboplatin & Nonsquamous & A & 100 & 10.5 & 0.95 (0.52 to I.74) \\
\hline & $\begin{array}{l}\text { or oxaliplatin in } \\
\text { nonsquamous }(A) \text { vs } \\
\text { squamous (B) }\end{array}$ & Squamous & B & 29 & 9.8 & \\
\hline & & & & & $\begin{array}{l}\text { Objective tumor } \\
\text { response } \\
(C R+P R+S D)\end{array}$ & $P$ value \\
\hline \multirow[t]{8}{*}{ Ciuleanu ${ }^{69}$} & Pemetrexed (A) vs BSC (B) & Adenocarcinoma & $A$ & 329 & $61.0 \%$ & \\
\hline & & & B & & $33.0 \%$ & $<0.001$ \\
\hline & & Large cell & A & 20 & $45.5 \%$ & \\
\hline & & & B & & $33.3 \%$ & 0.670 \\
\hline & & Squamous cell & A & 181 & $34.8 \%$ & \\
\hline & & & B & & $34.8 \%$ & 1.000 \\
\hline & & All nonsquamous & A & 482 & $51.7 \%$ & \\
\hline & & & B & & $33.3 \%$ & $<0.001$ \\
\hline
\end{tabular}

Abbreviations: BSC, best supportive care; CR, complete response; PR, partial response; SD, stable disease.

of the histologic subtypes showed that PC had significantly better survival than GC in patients with adenocarcinoma at 12.6 vs 10.9 months. Additionally, patients with large cell histology had significantly better survival in the PC group at 10.4 months vs 6.7 months for GC. Responses in squamous cell histologies showed preference to GC; however the results were not significant, with survival at 10.8 months in the GC group and 9.4 months in the PC group. These data are shown in Table 5 with associated hazard ratios. Data from these studies provided insight into diverse responses to pemetrexed in different NSCLC histologies. These findings have led to further prospective and retrospective studies evaluating this difference.

A retrospective analysis of two phase II studies of pemetrexed plus carboplatin or pemetrexed plus oxaliplatin chemonaive patients with advanced NSCLC was recently reported. ${ }^{68}$ The studies evaluated the regimens pemetrexed $500 \mathrm{mg} / \mathrm{m}^{2}$ plus carboplatin (AUC 6) given every 21 days or pemetrexed $500 \mathrm{mg} / \mathrm{m}^{2}$ plus oxaliplatin $120 \mathrm{mg} / \mathrm{m}^{2}$ every 21 days. Median overall survival was 10.5 months in the 
nonsquamous groups vs 9.8 months in the squamous groups. Progression-free survival was longer in the nonsquamous groups at 5.6 months vs 4.7 months in the nonsquamous groups. Results from this study are summarized in Table 5. These data further confirmed the findings in the previously mentioned studies.

A recent prospective phase III trial evaluated the use of maintenance pemetrexed vs best supportive care (BSC) in advanced NSCLC with subset analysis of each histologic subtype. ${ }^{69}$ In this trial, patients with advanced NSCLC were randomized (at a 2:1 ratio) to receive either pemetrexed $500 \mathrm{mg} / \mathrm{m}^{2}$ on day 1 , plus BSC or placebo on day 1 , plus BSC. The treatments were given on the typical 21-day cycle. Folic acid and vitamin B12 supplementation was given for all patients. Of the 663 patients enrolled, 441 received pemetrexed and 222 received placebo. Preliminary overall survival (with 55\% censoring for all patients) was 13.0 months with pemetrexed and 10.2 months with placebo. Pemetrexed was noted to have better efficacy in regards to progressionfree survival at 4.3 months vs 2.6 months in the placebo group. This was further analyzed for histologic subtypes. Progression-free survival overall for nonsquamous histologies was 4.5 months with pemetrexed vs 2.6 months for placebo. For adenocarciomas, progression-free survival was 4.7 months in the pemetrexed arm vs 2.6 months for placebo. Large-cell histologies had a progression-free survival of 3.5 months vs 2.1 months for placebo. All other histologies other than squamous had a progression-free survival of 4.2 months vs 2.8 months for placebo. Finally, it was noted that the patients with squamous histology had little difference in progressionfree survival with 2.8 months in the pemetrexed arm and 2.6 months in the placebo arm. These data, along with hazard ratios and objective tumor response, are noted in Table 5. There were no significant toxicity differences between the two groups other than grade 3-4 anemia (pemetrexed group 4.5\%, placebo group 1.4\%). The trial confirms that pemetrexed has better efficacy in nonsquamous histologies.

Another recent study done in Japan looked at the effect of increasing the dose of pemetrexed and the corresponding response in advanced NSCLC patients. ${ }^{70,71}$ Cox multiple regression analysis was done on all evaluable patients to identify prognostic factors for survival, this included histologic subtype (squamous vs nonsquamous). In this phase II trial, patients with advanced NSCLC were randomized to receive pemetrexed at a dose of $500 \mathrm{mg} / \mathrm{m}^{2}$ (P500) or $1,000 \mathrm{mg} / \mathrm{m}^{2}$ (P1000) on a 21 day cycle. The patients in this study received folic acid and vitamin B12 supplementation per protocol. Of the 216 patients evaluable for response, the objective tumor response rate was $18.5 \%$ in the P500 group vs $14.8 \%$ in the P1000 group. Median survival time for the P500 group was 16.0 months and for the P1000 group was 12.6 months. The subset analysis did not look at response rates for histology, but did evaluate median survival time. Patients with nonsquamous histology had a statistically significant, longer median survival time at 16.0 months vs 9.3 months for squamous histology. These data reported a hazard ratio of $1.90(P=0.00264,95 \% \mathrm{CI})$ for squamous/nonsquamous histology. Unfortunately, these subgroups were not further analyzed as it was not the primary endpoint of the study. Nevertheless, these data add to the observation that pemetrexed is showing more benefit in nonsquamous NSCLC histologies.

\section{Why difference in response to pemetrexed depends on NSCLC histologic subtype?}

The previously mentioned studies have shown an obvious clinical difference in efficacy and survival between nonsquamous and squamous cell histologies on NSCLC. Perhaps this is most easily illustrated by the recent phase III study lead by Ciuleanu which confirmed that maintenance pemetrexed had better efficacy in patients with nonsquamous histologic subtypes. ${ }^{69}$ Additionally, a recent retrospective study ${ }^{85}$ compared findings seen in two large phase III studies led by Scagliotti ${ }^{67}$ and Hanna. ${ }^{45}$ This large analysis provided further supportive information that pemetrexed shows a significant survival advantage in lung cancer patients with nonsquamous vs squamous histology. The analysis went on further to suggest that pemetrexed should not be used in lung cancer patients with squamous cell carcinoma.

These findings have stimulated further investigation into why this occurs. The molecular basis of cancer is an area of extreme interest currently. Advancements in molecular studies like real-time polymerase chain reaction (RT-PCR) and immunohistochemistry (IHC) allow scientists to evaluate tumors for characteristics that may make them sensitive to one therapy, but not another. Understanding the mechanism of action of pemetrexed has enabled work to be done to evaluate resistance mechanisms. As mentioned earlier, known resistance mechanisms for pemetrexed exist. Hypothetical resistance mechanisms can also alter folate metabolism in different cell types. One hypothesis under evaluation for pemetrexed resistance in squamous cell NSCLC is overexpression of thymidylate synthase (TS).

Several preclinical studies have shown that tumors that overexpress TS have decreased response to pemetrexed. ${ }^{72-74}$ Additionally, a recent preclinical study looked at in vitro 
chemosensitivity to pemetrexed in freshly explanted tumor cells. ${ }^{75}$ The study also did multiplex RT-PCR experiments for reduced folate carrier (RFC), folate receptor-alpha (FR-alpha), FPGS, TS, DHFR, GARFT, MRP 4, and MRP 5. The findings of the study found that lower levels of TS, GARFT, DHFR, and MRP 4 gene expression significantly correlated with chemosensitivity to pemetrexed. These data support the hypothesis that cells with higher expression of TS will be less sensitive to pemetrexed. Additionally, it raises the idea that expression of other key folate metabolism targets for pemetrexed, such as GARFT and DHFR, may play a role in resistance. The study also suggests that overexpression of major resistance proteins, such as MRP 4 can cause pemetrexed resistance.

Applying this information over to lung cancer, there was a recent evaluation of TS expression in NSCLC histologic subtypes. This study evaluated cellular TS expression in early-stage, resectable (stage I-IIIA), chemotherapy-naïve patients with lung adenocarcinoma and squamous cell lung carcinoma. ${ }^{76}$ Utilizing RT-PCR and IHC, mRNA quantification and protein expression for TS were evaluated in the tumors. The study reported that TS expression (both by mRNA levels and protein expression) was significantly higher in squamous cell carcinoma subtypes compared to adenocarcinomas. Another similar study looked further into TS expression in NSCLC. This study was designed to evaluate TS expression as a prognostic factor in patients with stage I, resected NSCLC. ${ }^{77}$ Histologic subtype analysis was done in this study as well. Utilizing IHC based on immunofluorescence combined with automated quantitative analysis (AQUA), TS protein expression was evaluated in resected NSCLC specimens. Additionally, TS mRNA quantification was performed on each sample using RT-PCR. The study showed that TS expression for both TS mRNA was significantly elevated in squamous cell histologies compared to lung adenocarcinomas. Additionally, the study showed that TS protein expression was slightly more elevated in squamous cell histologies than adenocarcinomas, but this was not statistically significant.

These prior studies support the hypothesis that TS expression is higher in NSCLC patients with squamous cell histologies. This led to further analysis in a clinical setting. An evaluation was done of the previously mentioned clinical study of cisplatin/gemcitabine vs cisplatin/pemetrexed. ${ }^{67}$ In this pharmacogenomic study, IHC was used to evaluate markers involved in the drug pathways targeted by other NSCLC treatments. TS expression was included in this study. Lower TS expression was associated with longer time to progression for the cisplatin/pemetrexed group $(P=0.014)$.
Further clinical studies done in small cell lung cancer (SCLC) support the hypothesis of TS expression affecting pemetrexed sensitivity. SCLC has shown minimal response to pemetrexed in a number of studies. ${ }^{79,80}$ In a recent study, SCLC has been shown to have very high TS expression. ${ }^{81}$ These data once again support the hypothesis for elevated TS expression decreasing the response to pemetrexed.

Although TS expression is the most studied mechanism of pemetrexed resistance in NSCLC, there are other hypotheses being evaluated. Factors such as deletion of methylthioadenosine phosphorylase, expression of key enzymes in folate metabolism, and major resistance proteins are being evaluated as potential resistance mechanisms to pemetrexed. ${ }^{82-84}$ These hypotheses are being evaluated in preclinical studies, but as of yet no clinical studies have shown a superior "marker" for pemetrexed resistance in a clinical setting. Further preclinical and clinical studies looking at these mechanisms must be performed to analyze the link between pemetrexed resistance and histologic subtype.

\section{Future directions: pemetrexed as a targeted therapy for NSCLC}

Based on favorable results from previous clinical trials, pemetrexed is currently a popular agent being evaluated for use in NSCLC. A number of clinical trials looking at the drug as monotherapy and in combination with other therapies are currently underway. Because of previous findings, most of these trials are focused on nonsquamous lung cancer histologies. Perhaps the most interesting trials are those that are looking into pemetrexed as a "targeted therapy" for nonsquamous cell lung cancer.

The National Cancer Institute is developing a study that is looking at pemetrexed as a targeted therapy for nonsquamous (NCT00798603). In this phase II clinical trial, older patients are planned to receive a combination of pemetrexed, carboplatin, and bevacizumab as first line therapy for advanced nonsquamous NSCLC. The primary objective of the study is to evaluate progression free survival with this regimen. Interestingly, the study has been designed to look at differences in efficacy, toxicity, and quality of life based on genetic polymorphisms in tumor type. The study aims to analyze tissue and blood samples of all patients to look at genes that encode proteins involved in the transport and activation of pemetrexed. Additionally, the study will analyze tissue samples to evaluate expression and polymorphisms in pemetrexed target genes including TS, DHFR, and GARFT. One can surmise that the results of this study may be helpful in determining which patients 
would benefit most from pemetrexed therapy. Additionally, it may lead to the development of tailored regimens based on differences in response in patients with various target gene expression.

Another study is aiming to tailor therapies utilizing genomic analysis prior to stratifying early-stage lung cancer patients for treatment with pemetrexed (NCT00545948). This phase II study will assign patients with early-stage NSCLC to treatment with cisplatin/vinorelbine or cisplatin/pemetrexed based on a genomic-based expression profile. This genomic analysis is hypothesized to predict chemotherapy sensitivity from tumor tissue samples. ${ }^{86,87}$ The study hopes to determine if it will be possible to pre-select patients that may respond to pemetrexed prior to initiation of therapy. If the study can to prove this, we could be closer to using pemetrexed as a tailored therapy based on tumor genetics.

Another area of clinical trial interest on the use of pemetrexed is pharmacogenomics. By understanding the variation in efficacy and toxicity of a certain drug in respect to genetic variation, we can hope to tailor therapies for each patient to ensure limited toxicity and increased efficacy. This concept is currently being applied in an ongoing phase II clinical trial evaluating the use of gemcitabine plus pemetrexed as a neoadjuvant therapy for patients with resectable NSCLC (NCT00226577). By analyzing the expression of genes associated with activation, inactivation, and efficacy of pemetrexed and gemcitabine, the study hopes to predict response and prognosis. Additionally, the study will analyze expression of these genes after chemotherapy to evaluate any alterations that may occur as a result of therapy. By making these analyses, the researches hope to obtain data that can lead to a more personalized approach towards the use of pemetrexed in patients with NSCLC.

\section{Conclusion}

As outlined in this review, pemetrexed has shown its utility as an effective drug for NSCLC. Analysis of its activity has revealed that patients with nonsquamous histologies benefit the most from the drug. Patients with squamous histology have not shown this benefit. Further inquiry into the molecular basis for this favorability for different histology has indicated that TS expression may play a role in tumor response, as patients with adenocarcinoma histologies typically have lower TS expression than those with squamous cell histology. Additional mechanisms that may associated with pemetrexed have been hypothesized, but lack strong experimental support at this time.
Based on the clinical activity observed in nonsquamous lung cancers, pemetrexed is currently approved for use in this histologic subtype.

With improving technology our comprehension of genomics and proteomics thrives. These disciplines have stimulated the growth of pharmacogenomics, which in turn has strengthened our ability to understand resistance mechanisms and modes of action for different drugs. As we investigate the molecular basis for clinical findings, we supplement our understanding of cancer. Ultimately, pharmacogenomic studies may be able to help us recognize which groups of patients with NSCLC will benefit the most from pemetrexed. The combination of clinical and translational research is the key to understanding which patients should receive this drug. Further studies looking at the genomic, proteomic, and pharmacogenomic variability of squamous and nonsquamous lung cancers should shed some light on their differences in drug response. As we strive to maximize response and improve the quality of life for each patient, molecular medicine will aid our quest towards personalized cancer care.

\section{Disclosures}

The authors declare no conflicts of interest.

\section{References}

1. Shepherd FA. Screening, diagnosis, and staging of lung cancer. Curr Opin Oncol. 1993;5(2):310-322.

2. Memal A, Murray T, Wand E, et al. Cancer Statistics, 2005. Ca Cancer J Clin. 2005;55:10-30.

3. Ettinger D, Johnson B. Update: NCCN small cell and non-small cell lung cancer Clinical Practice Guidelines. J Natl Compr Canc Netw. 2005;3 Suppl 1:S17-S21.

4. Schiller JH, Harrington D, Belani CP, Langer C, Sandler A, Krook J, et al. Comparison of four chemotherapy regimens for advanced non-small-cell lung cancer. N Engl J Med. 2002;346:92-98.

5. Sandler A, Gray R, Perry MC, et al. Paclitaxel-carboplatin alone or with bevacizumab for non small cell lung cancer. $N$ Engl $J$ Med. 2006;355:2542-2550.

6. Shepherd FA, Rodrigues Pereira J, Ciuleanu T, et al. Erlotinib in previously treated non-small-cell lung cancer. $N$ Engl J Med. 2005;353:123-132.

7. Shigematsu H, Gazdar AF. Somatic mutations of epidermal growth factor receptor signaling pathway in lung cancers. Int $J$ Cancer. 2006;118(2):257-262.

8. Peterson P, Park K, Fossella FV, et al. Is pemetrexed more effective in patients with non-squamous histology. A retrospective analysis of a phase III trial of pemetrexed vs docetaxel in previously treated patients with advanced NSCLC. Eur J Cancer Suppl. 2007;5:363. Abstract p. 6521.

9. Hanauske AR, Chen V, Paoletti P, et al. Pemetrexed disodium: a novel antifolate clinically active against multiple solid tumors. Oncologist. 2001;6:363-373.

10. Chattopadhyay S, Moran RG, Goldman ID. Pemetrexed: biochemical and cellular pharmacology, mechanisms, and clinical applications. Mol Cancer Ther. 2007;6:404-417. 
11. Chu E, Mota AC, Fogarasi MC. Pharmacology of cancer chemotherapy: antimetabolites. In: Devita VT, Hellman S, Rosenberg SA, editors. Cancer: Principles and Practice of Oncology, 6th ed. Philadelphia: Lippincott Williams and Wilkins; 1993. p. 388-415.

12. McGuire JJ. Anticancer antifolates: current status and future directions. Curr Pharm Des. 2003;9:2593-613.

13. Zhao R, Babani S, Gao F, et al. The mechanism of transport of the multitargeted antifolate (MTA) and its cross-resistance pattern in cells with markedly impaired transport of methotrexate. Clin Cancer Res. 2000;6:3687-3695.

14. Schilsky RL. Antimetabolites. In: Perry MC, editor. The Chemotherapy Source Book. Baltimore: Williams \& Wilkins; 1992. p. 301-315.

15. Shih C, Chen VJ, Gossett LS, et al. LY231514, a pyrrolo[2,3-d] pyrimidine-based antifolate that inhibits multiple folate-requiring enzymes. Cancer Res. 1997;57:1116-1123.

16. Rollins KD, Lindley C. Pemetrexed: a multitargeted antifolate. Clin Ther. 2005;27:1343-1382.

17. Goldman ID, Zhao R. Molecular, biochemical, and cellular pharmacology of pemetrexed. Semin Oncol. 2002;29 Suppl 18:3-17.

18. Adjei AA. Pemetrexed (ALIMTA). A novel multitargeted antineoplastic agent. Clin Cancer Res. 2004;10(12 Pt 2):4276s-4280s.

19. Hazarika M, White RM, Johnson JR, Pazdur R. FDA drug approval summaries: pemetrexed (Alimta). Oncologist. 2004;9:482-488.

20. Ouellet D, Periclou AP, Johnson RD, et al. Population pharmacokinetics of pemetrexed disodium (Alimta) in patients with cancer. Cancer Chemother Pharmacol. 2000;46:227-234.

21. Alimta (pemetrexed) [product information]. Indianapolis, Ind: Eli Lilly and Company; 2004.

22. Wielinga P, HooijbergJH, Gunnarsdottir S, et al. The human multidrug resistance protein MRP5 transports folates and can mediate cellular resistance against antifolates. Cancer Res. 2005;65: 4425-4430.

23. Wang Y, Zhao R, Goldman ID. Decreased expression of the reduced folate carrier and folypolyglutamate synthetase is the basis for acquired resistance to the pemetrexed antifolate (LY231514) in an L1210 murine leukemia cell line. Biochem Pharmacol. 2003;65:1163-1170.

24. Rhee MS, Ryan TJ, Galivan J. Glutamyl hydrolase and the multitargeted antifolate LY231514. Cancer Chemother Pharmacol. 1999;44: $427-432$

25. Worzalla JF, Shih C, Schultz RM. Role of folic acid in modulating the toxicity and efficacy of' the multitargeted antifolate, LY231514. Anticancer Res. 1998;18:3235-3239.

26. Rusthoven JJ, Eisenhauer E, Butts C, et al. Multitargeted antifolate LY2311514 as first line chemotherapy for patients with advanced non small cell lung cancer: phase II study. J Clin Oncol. 1999;17: 1194-1199.

27. Chattopadhyay S, Tamari R, Min SH, et al. Commentary: a case for minimizing folate supplementation in clinical regimens with pemetrexed based on the marked sensitivity of the drug to folate availability. Oncologist. 2007;12:808-815.

28. Socinski MA, Raju RN, Neubauer M, et al. Pemetrexed in relapsed small-cell lung cancer and the impact of shortened vitamin supplementation lead-in time: results of a phase II trial. J Thorac Oncol. 2008;3:1308-1316.

29. Clarke SJ, Abratt R, Goedhals L, et al. Phase II trial of pemetrexed disodium (ALIMTA, LY231514) in chemotherapy-naïve patients with advanced non-small-cell lung cancer. Ann Oncol. 2002;13: 737-741.

30. Gridelli C, Kaukel E, Gregorc V, et al. Single-agent pemetrexed or sequential pemetrexed/gemcitabine as front-line treatment of advanced non-small cell lung cancer in elderly patients or patients ineligible for platinum-based chemotherapy: a multicenter, randomized, phase II trial. J Thorac Oncol. 2007;2:221-229

31. Manegold C, Gatzemeier U, von Pawel J, et al. Front-line treatment of advanced non-small-cell lung cancer with MTA (LY231514, pemetrexed disodium, ALIMTA) and cisplatin: a multicenter phase II trial. Ann Oncol. 2000;11:435-440.
32. Shepherd FA, Dancey J, Arnold A, et al. Phase II study of pemetrexed disodium, a multitargeted antifolate, and cisplatin as first-line therapy in patients with advanced nonsmall cell lung carcinoma: a study of the National Cancer Institute of Canada Clinical Trials Group. Cancer. 2001;92:595-600.

33. Monnerat C, Le Chevalier T, Kelly K, et al. Phase II study of pemetrexed-gemcitabine combination in patients with advancedstage non-small cell lung cancer. Clin Cancer Res. 2004;10: 5439-5446.

34. Ma CX, Nair S, Thomas S, et al. Randomized phase II trial of three schedules of pemetrexed and gemcitabine as front-line therapy for advanced non-small-cell lung cancer. J Clin Oncol. 2005;23: 5929-5937.

35. Treat J, Bonomi P, McCleod M, et al. Administration of pemetrexed immediately following gemcitabine as front-line therapy in advanced NSCLC: a phase II Trial. Lung Cancer. 2006;53:77-83.

36. McCleod M, Treat J, Christiansen N, et al. Pemetrexed (P) plus gemcitabine $(\mathrm{G})$ as front-line chemotherapy for patients with locally advanced or metastatic nonsmall cell lung cancer (NSCLC): a phase II clinical trial. J Clin Oncol. 2005; ASCO Annual Meeting Proceedings Vol 23, No. 16S, Part I of II (June 1 Suppl):7121.

37. West HL, Wakelee HA, Perry MC, et al. Gemcitabine and pemetrexed administered in rapid sequence as front-line chemotherapy for advanced non-small-cell lung cancer: a phase II clinical trial. Ann Oncol. 2009 Jan 15

38. Dudek AZ, Larson T, McCleod MJ, et al. Phase $1 / 2$ dose escalating study of twice-monthly pemetrexed and gemcitabine in patients with advanced cancer and non-small cell lung cancer. J Thorac Oncol. 2008;3:394-399.

39. Gridelli C, Kaukel E, Gregorc V, et al. Single-agent pemetrexed or sequential pemetrexed/gemcitabine as front-line treatment of advanced non-small cell lung cancer in elderly patients or patients ineligible for platinum-based chemotherapy: a multicenter, randomized, phase II trial. J Thorac Oncol. 2007;2:221-229.

40. Blakely LJ, Schwartzberg L, Keaton M, et al. A phase II trial of pemetrexed and gemcitabine as first line therapy for poor performance status and/or elderly patients with stage IIIB/IV non-small cell lung cancer. Lung Cancer. 2009 Jan 21. [Epub ahead of print]

41. Depierre A, Chastang C, Quoix E, et al. Vinorelbine versus vinorelbine plus cisplatin in advanced non-small cell lung cancer: a randomized trial. Ann Oncol. 1994;5:37-42.

42. Clarke SJ, Boyer MJ, Millward M, et al. A phase I/II study of pemetrexed and vinorelbine in patients with non small cell lung cancer. Lung Cancer. 2005;49:401-412.

43. Smit EF, Mattson K, von Pawel J, et al. ALIMTA (pemetrexed disodium) as second-line treatment of non-small-cell lung cancer: a phase II study. Ann Oncol. 2003;14:455-460.

44. Shepherd FA, Dancey J, Ramlau R, et al. Prospective randomized trial of docetaxel versus best supportive care in patients with non-small-cell lung cancer previously treated with platinum-based chemotherapy. J Clin Oncol. 2000;18:2095-2103.

45. Hanna N, Shepherd FA, Fossella FV, et al. Randomized phase III trial of pemetrexed versus docetaxel in patients with non small cell lung cancer previously treated with chemotherapy. J Clin Oncol. 2004;22:1589-1597.

46. Cohen MH, Johnson JR, Wang YC, et al. FDA drug approval summary: pemetrexed for injection (Alimta) for the treatment of non-small cell lung cancer. Oncologist. 2005;10:363-368.

47. de Marinis F, Pereira JR, Fossella F, et al. Lung Cancer Symptom Scale outcomes in relation to standard efficacy measures: an analysis of the phase III study of pemetrexed versus docetaxel in advanced non-small cell lung cancer. J Thorac Oncol. 2008;3:30-36.

48. Pujol JL, Paul S, Chouaki N, et al. Survival without common toxicity criteria grade $3 / 4$ toxicity for pemetrexed compared with docetaxel in previously treated patients with advanced non-small cell lung cancer (NSCLC): a risk-benefit analysis. J Thorac Oncol. 2007;2: $397-401$. 
49. Cullen MH, Zatloukal P, Sörenson S, et al. A randomized phase III trial comparing standard and high-dose pemetrexed as second-line treatment in patients with locally advanced or metastatic non-small-cell lung cancer. Ann Oncol. 2008;19:939-945.

50. Manegold C, Gatzemeier U, von Pawel J, et al. Front-line treatment of advanced non-small-cell lung cancer with MTA (LY231514, pemetrexed disodium, ALIMTA) and cisplatin: a multicenter phase II trial. Ann Oncol. 2000;11:435-440.

51. Shepherd FA, Dancey J, Arnold A, et al. Phase II study of pemetrexed disodium, a multitargeted antifolate, and cisplatin as first-line therapy in patients with advanced nonsmall cell lung carcinoma: a study of the National Cancer Institute of Canada Clinical Trials Group. Cancer. 2001;92:595-600

52. Scagliotti GV, Kortsik C, Dark GG, et al. Pemetrexed combined with oxaliplatin or carboplatin as first-line treatment in advanced NSCLC: a multicenter, randomized, phase II trial. Clin Can Res. 2005;11: 690-696.

53. Koshy S, Herbst RS, Obasaju CK, et al. A phase II trial of pemetrexed plus carboplatin in patients with advanced non small cell lung cancer. J Clin Oncol. 2004; ASCO Annual Meeting Proceedings (Post-Meeting Edition). Vol 22, No 14S (July 15 Suppl):7074.

54. Zinner RG, Fossella FV, Gladish GW, et al. Phase II study of pemetrexed in combination with carboplatin in the first-line treatment of advanced NSCLC. Cancer. 2005;104:2449-2456.

55. Socinski MA, Weissman C, Hart LL, et al. Randomized phase II trial of pemetrexed combined with either cisplatin or carboplatin in untreated extensive-stage small-cell lung cancer. J Clin Oncol. 2006;24: 4840-4847.

56. Gronberg BH, Bremnes R, Aasebo U, et al. Pemetrexed plus carboplatin versus gemcitabine plus carboplatin in the treatment of stage IIIB/IV NSCLC [oral presentation]. XX meeting, J Clin Oncol. 2007; ASCO Annual Meeting Proceedings Part I. Vol 25, No. 18S (June 20 Suppl):7517.

57. Scagliotti G, Parikh P, von Pawel J, et al. Phase III study comparing cisplatin plus gemcitabine with cisplatin plus pemetrexed in chemotherapy-naive patients with advanced-stage NSCLC. $J$ Clin Oncol. 2008;26:3485-3486.

58. Smit E, Groen H, Smith H, et al. A randomized phase II study of pemetrexed (P) versus pemetrexed-carboplatin (PC) as second line treatment for patients (pts) with advanced non-small-cell lung cancer (NSCLC)NVALT 7. J Clin Oncol. 2008;26(May 20 Suppl):abstr 8050.

59. Herbst RS, O’Neill VJ, Fehrenbacher L, et al. Phase II study of efficacy and safety of bevacizumab in combination with chemotherapy or erlotinib compared with chemotherapy alone for treatment of recurrent or refractory non small-cell lung cancer. J Clin Oncol. 2007;25:4743-4750.

60. Weiss GJ, Zeng C, Kelly K, et al. Single-institution experience with pemetrexed and bevacizumab as salvage therapy in advanced nonsmall-cell lung cancer. Clin Lung Cancer. 2007;8:335-338.

61. Heist RS, Fidias P, Huberman M, et al. A phase II study of oxaliplatin, pemetrexed, and bevacizumab in previously treated advanced non-small cell lung cancer. $J$ Thorac Oncol. 2008;3:1153-1158.

62. de Boer R, Humblet Y, Wolf J, et al. An open-label study of vandetanib with pemetrexed in patients with previously treated non-small-cell lung cancer. Ann Oncol. 2009;20:486-491.

63. Jalal SI, Waterhouse D, Edelman M, et al. Pemetrexed plus cetuximab in patients (pts) with recurrent non-small cell lung cancer (NSCLC): A phase I-IIa dose-ranging study from the Hoosier Oncology Group. $J$ Clin Oncol. 2007; ASCO Annual Meeting Proceedings Part I. Vol 25, No. 18S (June 20 Suppl):7698.

64. Hirsch FR, Spreafico A, Novello S, et al. The prognostic and predictive role of histology in advanced non-small cell lung cancer: a literature review. J Thorac Oncol. 2008;3:1468-14681.

65. Peterson P, Park K, Fossella F, et al. Is pemetrexed more effective in adenocarcinoma and large cell lung cancer than in squamous cell carcinoma? A retrospective analysis of a phase III trial of pemetrexed vs docetaxel in previously treated patients with advanced non-small cell lung cancer (NSCLC) [abstract]. J Thorac Oncol. 2007;2:S851.
66. Scagliotti G, Parikh P, von Pawel P, et al. Phase III study of pemetrexed plus cisplatin versus gemcitabine plus cisplatin in chemonaive patients with locally advanced or metastatic non-small cell lung cancer (NSCLC) [abstract]. J Thorac Oncol. 2007;2:S306

67. Scagliotti G, Parikh P, von Pawel P, et al. Phase III study comparing cisplatin plus gemcitabine with cisplatin plus pemetrexed in chemotherapy-naïve patients with advanced-stage non-small-cell lung cancer. J Clin Oncol. 26:2008;3543-3551.

68. Peng G, Zinner RG,Wang Y, et al. Comparison of patient outcomes stratified by histology among pemetrexed (P)-treated patients (pts) with stage IIIB/IV non-small cell lung cancer (NSCLC) in two phase II trials. J Clin Oncol. 2008;26(May 20 Suppl):abstr 8096.

69. Ciuleanu TE, Brodowicz T, Belani CP, et al. Maintenance pemetrexed plus best supportive care (BSC) versus placebo plus BSC: A phase III study. J Clin Oncol. 2008;26(May 20 Suppl): abstr 8011.

70. Okabe T, Kubota K, Tamura T, et al. Prognostic factors affecting survival on pretreated patients with locally advanced or metastatic nonsmall cell lung cancer (NSCLC) - Subgroup analysis in a randomized $\mathrm{Ph}$ II study of pemetrexed $500 \mathrm{mg} / \mathrm{m}^{2}$ and $1000 \mathrm{mg} / \mathrm{m}^{2}$ [abstract]. Eur J Cancer Suppl. 2007;5:376.

71. Ohe Y, Ichinose Y, Nakagawa K, et al. Efficacy and safety of two doses of pemetrexed supplemented with folic acid and vitamin B12 in previously treated patients with non-small cell lung cancer. Clin Cancer Res. 2008;14:4206-4212.

72. Schultz RM, Chen VJ, Bewley JR, et al. Biological activity of the multitargeted antifolate, MTA (LY231514), in human cell lines with different resistance mechanisms to antifolate drugs. Semin Oncol. 1999;26(2 Suppl 6):68-73.

73. Giovannetti E, Mey V, Nannizzi S, et al. Cellular and pharmacogenetics foundation of synergistic interaction of pemetrexed and gemcitabine in human non-small-cell lung cancer cells. Mol Pharmacol. 2005;68: $110-118$.

74. Sigmond J, Backus HH, Wouters D, et al. Induction of resistance to the multitargeted antifolate Pemetrexed (ALIMTA) in WiDr human colon cancer cells is associated with thymidylate synthase overexpression. Biochem Pharmacol. 20031;66:431-438.

75. Hanauske AR, Eismann U, Oberschmidt O, et al. In vitro chemosensitivity of freshly explanted tumor cells to pemetrexed is correlated with target gene expression. Invest New Drugs. 2007;25:417-423.

76. Ceppi P, Volante M, Saviozzi S, et al. Squamous cell carcinoma of the lung compared with other histotypes shows higher messenger RNA and protein levels for thymidylate synthase. Cancer. 2006;107:1589-1596.

77. Zheng Z, Li X, Schell MJ, et al. Thymidylate synthase in situ protein expression and survival in stage I nonsmall-cell lung cancer. Cancer. 2008;112:2765-2773.

78. Scagliotti G, Kaiser C, Biesma B, et al. Correlations of biomarker expression and clinical outcome in a large phase III trial of pemetrexed plus cisplatin or gemcitabine plus cisplatin in chemonaive patients with locally advanced or metastatic non-small cell lung cancer (NSCLC) [abstract]. J Thorac Oncol. 2007;2:S375.

79. Grønberg BH, Bremnes RM, Aasebø U, et al. A prospective phase II study: high-dose pemetrexed as second-line chemotherapy in small-cell lung cancer. Lung Cancer. 2009;63:88-93.

80. Hanna NH, Ansari R, Bhatia S, et al. Pemetrexed in patients (pts) with relapsed small cell lung cancer (SCLC): A phase II study from the Hoosier Oncology Group. J Clin Oncol. 2006; ASCO Annual Meeting Proceedings Part I. Vol 24, No. 18S (June 20 Suppl): 7063.

81. Ceppi P, Volante M, Ferrero A, et al. Thymidylate synthase expression in gastroenteropancreatic and pulmonary neuroendocrine tumors. Clin Cancer Res. 2008;14:1059-1064.

82. Schmid M, Sen M, Rosenbach MD, et al. A methylthioadenosine phosphorylase (MTAP) fusion transcript identifies a new gene on chromosome 9p21 that is frequently deleted in cancer. Oncogene. 2000;19:5747-5754.

83. Chattopadhyay S, Zhao R, Tsai E, et al. The effect of a novel transition state inhibitor of methylthioadenosine phosphorylase on pemetrexed activity. Mol Cancer Ther. 2006;5:2549-2555. 
84. Assaraf YG. Molecular basis of antifolate resistance. Cancer Metastasis Rev. 2007;26:153-181.

85. Scagliotti G, Hanna N, Fossella F, et al. The differential efficacy of pemetrexed according to NSCLC histology: a review of two Phase III studies. Oncologist. 2009;14(3):253-263.
86. Potti A, Mukherjee S, Petersen R, et al. A genomic strategy to refine prognosis in early-stage non-small-cell lung cancer. $N$ Engl $J$ Med. 2006;355:570-80. Erratum in: N Engl J Med. 2007;356:201-202.

87. Potti A, Dressman HK, Bild A, et al. Genomic signatures to guide the use of chemotherapeutics. Nat Med. 2006;12:1294-1300.

\section{Publish your work in this journal}

Pharmacogenomics and Personalized Medicine is an international, peer-reviewed, open access journal characterizing the influence of genotype on pharmacology leading to the development of personalized treatment programs and individualized drug selection for improved safety, efficacy and sustainability. This journal is indexed on the
American Chemical Society's Chemical Abstracts Service (CAS). The manuscript management system is completely online and includes a very quick and fair peer-review system, which is all easy to use. Visit http://www.dovepress.com/testimonials.php to read real quotes from published authors.

Submit your manuscript here: http://www.dovepress.com/pharmacogenomics-and-personalized-medicine-journal 